\title{
Integrating Library Instruction into the Course Management System for a First-Year Engineering Class: An Evidence-Based Study Measuring the Effectiveness of Blended Learning on Students' Information Literacy Levels
}

\section{Qinqin Zhang, Maren Goodman, and Shiyi Xie}

This research examines students in a first-year engineering course who receive library instruction by using a newly developed online module and attending optional in-person tutorials. It aims to evaluate the outcomes of library information literacy instruction using this module combined with in-person help. Results show a significant improvement in information literacy skills from a pre-test to a post-test. Focus group and survey data indicate that most students preferred the self-paced learning style of the online module and that the content of the module helped them to conduct library research for the course. This study also considers best practices for online library instruction. A blended instruction approach provides students with the flexibility to learn from a variety of formats at their own pace and also reduces library staff workload, especially for a large course.

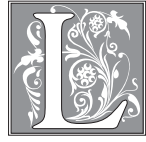

ibrary services and instruction are facing a new era where many of our users are no longer physically in front of us. Ubiquitous web technologies have brought a revolutionary change in terms of how we provide our services and how we deliver information literacy instruction. Academic libraries have been increasingly involved in e-learning initiatives to develop technology-enabled teaching and learning.

This research study was conducted at the University of Western Ontario (Western) in London, Ontario, Canada. As a member of the Association of Research Libraries, Western is a research-intensive university with 10 faculties and more than 35,000 undergraduate and graduate students. Western Libraries has eight service locations across its main campus in London, Ontario, one of which is Allyn and Betty Taylor Library (Taylor Library), which supports four faculties including the Faculty of Engineering.

Western faces the same reality as many other institutions: growth of the student population, shortage of library staff, and promotion of e-learning initiatives. In fall 2012,

Qinqin Zhang and Shiyi Xie are Research and Instructional Services Librarians at the University of Western Ontario; Maren Goodman is a Clinical Librarian at London Health Sciences Centre; e-mail: qinqin. zhang@uwo.ca, maren.goodman@lhsc.on.ca, shiyi.xie@uwo.ca. (2015 Qinqin Zhang, Maren Goodman, and Shiyi Xie, Attribution-NonCommercial (http://creativecommons.org/licenses/by-nc/3.0/) CC BY-NC. 
a short-term e-learning working group within Western Libraries made recommendations on how Western Libraries can move forward with e-learning initiatives. In May 2013, a universitywide e-learning task force developed a report to the provost, which demonstrated strong support for e-learning initiatives at Western. Within the Western community, the Faculty of Engineering has an Assistant Dean of IT and E-Learning to promote and support the e-learning initiatives of the faculty, which the engineering liaison librarians at Taylor Library have been well aware of.

The targeted curriculum for this research study was a year-long, first-year general engineering course offered by the Faculty of Engineering at Western: Engineering Science 1050 (ES1050), Introductory Engineering Design and Engineering Studio. The course has a major assignment, the State-of-the-Art report (SOTA report), along with a search log assignment. Librarians and library assistants from Taylor Library have integrated inperson library instruction into this course in the past. Previously, engineering librarians delivered information literacy instruction during lab sessions of the course. In summer 2012, due to staff shortages and in support of the e-learning initiatives mentioned above, Taylor Library decided to transform the in-person instruction for this course into an online library module to cover the same content. The online library module was intended to be embedded as part of the ES1050 course site in Online Western Learning (OWL powered by Sakai), the Course Management System (CMS) at Western. In addition to the online content, we also planned to hold several library tutorial sessions to provide the students with in-person research support. This study was conducted during the 2012-2013 academic year, when 413 students were enrolled in ES1050.

ACRL Guidelines for Instruction Programs in Academic Libraries provides academic libraries with guidelines for developing effective instructional programs. In its discussion of program design, it indicates that "instruction should employ active learning strategies and techniques" and "learning styles should be considered and multiple modes should be incorporated whenever possible." ${ }^{1}$ The ACRL Guidelines lists several instructional modes that can be used to deliver library instruction, including: web tutorials or web-based instruction, asynchronous/synchronous modes of instruction, course management software for instruction, and hybrid or blended learning ("blended learning" hereafter). In keeping with these recommendations, the delivery mode of the ES1050 library instruction was designed to facilitate blended learning, including an online library module, a brief in-class presentation, and several optional in-person library tutorial sessions.

\section{Literature Review}

Science and engineering disciplines change rapidly, so it is important for students in these disciplines to acquire information literacy skills. These skills help students keep up with new developments and new sources of research data not only in their academic studies but also in their future careers in these fields. ${ }^{2}$ Previous research has asked questions about delivery mode, embedding library instruction in CMS, the challenges of library instruction for science and engineering students, and assessing and evaluating online or blended library instruction.

Several studies examine and compare the effectiveness of information literacy instruction in various delivery modes and find online instruction as effective as faceto-face instruction. ${ }^{3}$ However, a concern with online-only instruction is that students do not get a chance to meet a librarian in person, which may influence their referenceseeking habits later on. ${ }^{4}$ For this reason, other researchers are more in favour of a blended approach with greater opportunities for in-person instruction. ${ }^{5}$ The blended approach is linked to improved performance and higher test scores. ${ }^{6}$ It can also make library instruction flexible and facilitate student learning. ${ }^{7}$ 
As online information literacy instruction becomes more commonplace, researchers have assembled some best practices and guidelines for effective online information literacy program design. Wittkopf considers current practices for providing online courses using the following principles: learning goals and content presentation, interactions, assessment and measurement, instructional media and tools, and learner support systems and services. ${ }^{8}$ Mery, Newby, and Peng believe that information literacy can be taught effectively through a well-designed online course, which requires a thoughtful course design, the capacity to create online learning modules, and the ability to train qualified teaching assistants to help students. ${ }^{9}$ Held draws attention to some "pillars of effective information literacy instruction" that must be considered when designing library instruction services, including collaboration with faculty, assessment of the library instruction, student responses to online library instruction, and attention to instructional design so that online tutorials are effective and keep student engagement in mind. ${ }^{10}$

Michel summarizes the advantages and disadvantages of the use of asynchronous online tutorials in library instruction: online tutorials are accessible anytime, anywhere, allowing students or faculty to learn library skills at their own pace and saving librarians' instruction time. ${ }^{11}$ On the other hand, online tutorials lack personal interaction between librarians and students, and developing effective online tutorials requires advanced web design technologies and usability testing, which demand substantial staffing time.

Libraries have typically taken either a micro or macro approach to integrating library instruction into CMS, providing students with either general library links (macro) or course-specific information (micro). ${ }^{12}$ Several researchers recommend presenting library resources in a course- or assignment-centered context. ${ }^{13}$ Course management systems allow for maximum exposure of these course-centered library resources in a convenient place. ${ }^{14}$ Library videos are also often embedded within the CMS environment. Henrich and Attebury find that video tutorials are effective at delivering information literacy content and increasing students' confidence and, thus, are worth the time and effort to create. ${ }^{15}$

There are some special challenges for library instruction in science and engineering disciplines. An American Library Association (ALA), Association of College and Research Libraries (ACRL), and Science \& Technology Section (STS) task force noted that "science, engineering, and technology disciplines pose unique challenges in identifying, evaluating, acquiring and using information." 16 The resulting document, Information Literacy Standards for Science and Engineering/Technology, defines information literacy in science-, engineering-, and technology-related disciplines as "a set of abilities to identify the need for information, procure the information, evaluate the information and subsequently revise the strategy for obtaining information, to use the information and to use it in an ethical and legal manner, and to engage in lifelong learning." ${ }^{17}$ Barr reflects on library instruction at Harvard University's science libraries and notes the challenge of online library instruction given the dynamic nature of science research, which necessitates frequent updating of information, keeping up with changing courses and content, and understanding new technologies. ${ }^{18}$ Barsky, Read, and Greenwood focus on library instruction for undergraduate engineering students, arguing that in-person instruction is essential and must be combined with detailed course pages tailored to each class. ${ }^{19}$ They stress the importance of reaching students in the first two years of their studies to effectively teach them about library resources specifically for engineers.

Once online or blended library instruction has been designed and implemented, it is necessary to assess and evaluate the instruction design so that it can be revised 
and improved for future students. Several researchers have used pre- and post-tests to assess student learning. ${ }^{20}$ According to Henrich and Attebury, the use of pre- and post-tests in CMS on a fixed group of students is a helpful assessment approach for online instruction. ${ }^{21}$ Kraemer, Lombardo, and Lepkowski indicate that using course management tools for library instruction provides librarians with the convenience of embedding evaluations for student learning outcomes and storing and analyzing the results. ${ }^{22}$ Anderson and May investigate the effectiveness of delivery methods in information literacy instruction by evaluating students' cognitive learning with preand post-tests, but they also measure behavior learning outcomes, the ability to apply concepts to specific assignments, using two course-specific assignments. ${ }^{23}$ Clark and Chinburg find that citation analysis can also be done on term papers to assess the learning outcomes in students who receive library instruction through face-to-face versus online delivery modes in a course. ${ }^{24}$ They conducted a citation analysis categorizing and counting both the citations and the sources cited in undergraduate students' papers, and they recommend citation analysis as an effective way of assessing the effectiveness of library instruction in various forms of library teaching.

Some of the literature we reviewed focuses on online library instruction for first-year students, but there is little literature on library instruction for first-year engineering students in particular. Only Barsky, Read, and Greenwood focus on library instruction designed for students early in an undergraduate engineering program. ${ }^{25}$ Our study bridges the literature gap by examining the effectiveness of blended learning on firstyear engineering students' information literacy levels.

\section{Development of the ES1050 Library Instruction}

In summer 2012, a team of three librarians and one library assistant from Taylor Library assumed responsibility for developing an online library module for the ES1050 course. We contacted the course coordinator, who was also one of the course instructors, and gained the faculty's full support for this e-learning project. During the initial meeting with the course coordinator, we consulted about the content of the library module. The library module is targeted to help students with their ES1050 course assignments, including a SOTA report on a specific engineering design topic and a search log assignment to record their information searching process on their chosen topic.

The team planned the module content based on our past experience working with the undergraduate engineering students and familiarity with the course and its assignments. The learning outcomes of the library module and relevant assignments were designed to align with the five standards of the Information Literacy Standards for Science and Engineering/Technology. ${ }^{26}$ ES1050 library instruction would help students to be able to:

- recognize the importance of scholarly information sources for a research topic;

- build search strategies using appropriate search terms and Boolean operators with a concept map and a search strategy worksheet as tools;

- apply search strategies effectively in relevant information resources;

- $\quad$ keep track of literature searches with a search log;

- evaluate information sources through the CRAAP (Currency, Relevance, Accuracy, Authority, and Purpose $)^{27}$ process; and

- understand information sources, and cite them properly.

The team divided the module content into several sections covering basic library and information literacy-related topics, such as evaluating sources, comparing scholarly and popular sources, finding books and journal articles, citing properly using APA style, and so on. (See figure 1 for the homepage of the module.) The module included plain HTML text, interactive HTML text, images, and videos. Before developing the 
module, we presented the proposed content to the course coordinator and received his approval and positive feedback.

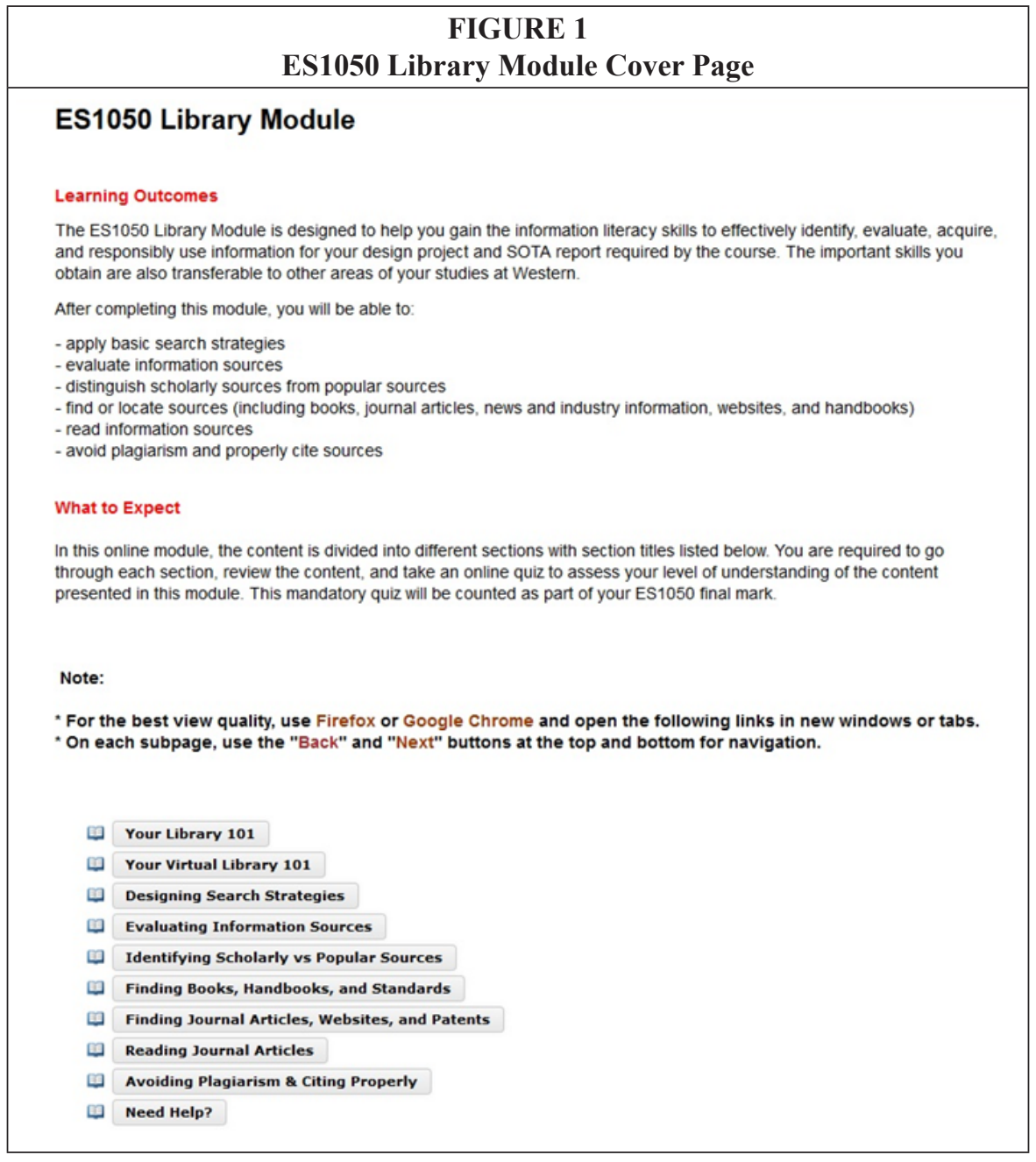

As part of the module content, we embedded existing library tutorial videos in Sakai. Most of these videos were developed by Western Libraries staff on various topics, such as using Boolean operators, the peer review process, and introduction to call numbers. Some of the videos were made in-house by library staff using software programs including Camtasia, and some others were developed by library staff in collaboration with the Instructional Technology Resources Centre (ITRC) at Western. All these videos were loaded to and accessible via YouTube, which allowed us to simply embed them as YouTube videos on the module pages. In this module, only one video was produced by a third-party source that the library subscribed to, a video about plagiarism by Films on Demand. We instructed users to log in to off-campus access to view this licensed video while off campus. (See figure 2 for an example of a module page with video embedded.) 


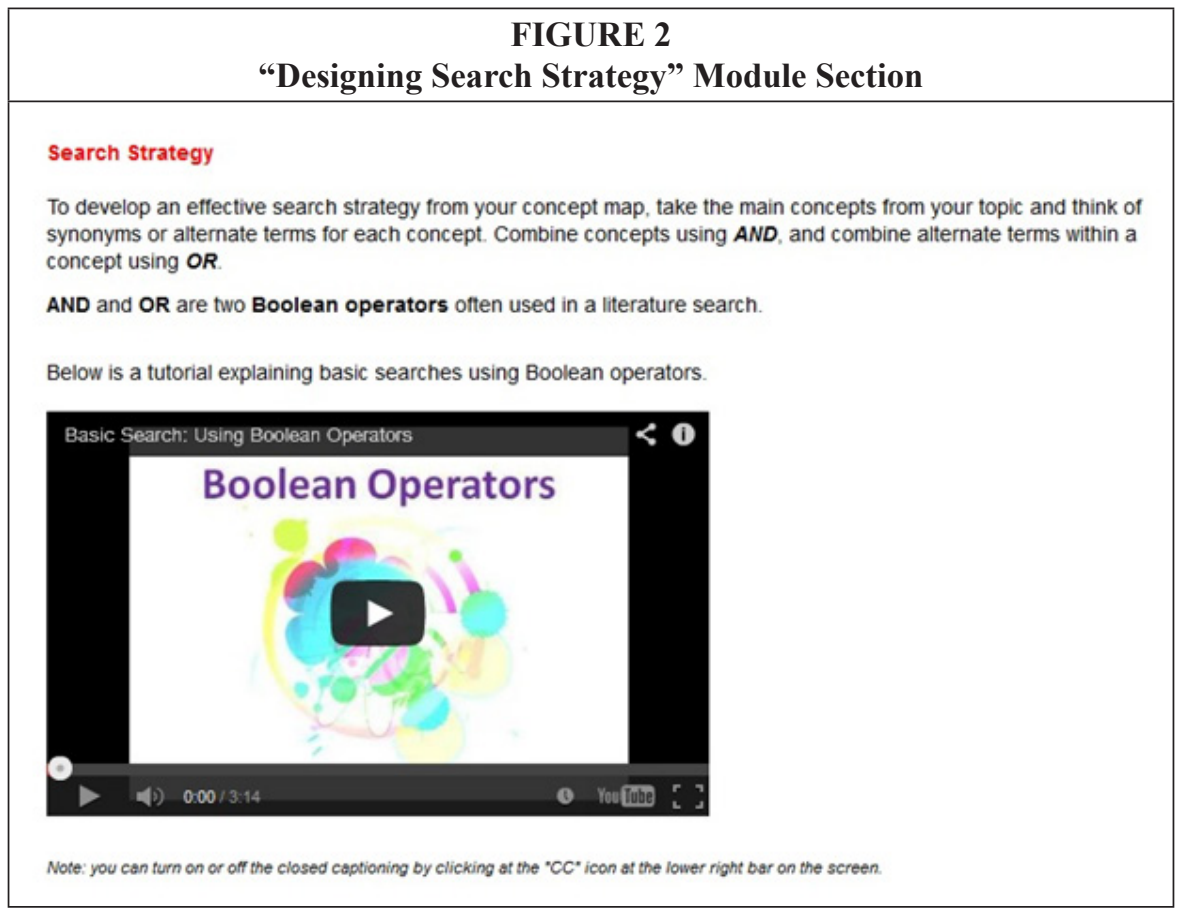

During development, we also consulted with the ITRC at Western and Western Libraries' Library Information Technology Services (LITS) for technical assistance, especially for the creation of subpages in Sakai and the development of programming codes supporting the interactive HTML content in the module. (See figure 3 for a screenshot of the module page with interactive HTML content.)

\begin{tabular}{|c|}
\hline FIGURE 3 \\
Module Page with Interactive HTML Content \\
\hline Journal article citation (paginated by issue): \\
Article Title \\
Delson, N. J. (2001). Increasing team motivation in \\
engineering design courses. International Journal of \\
Engineering Education, 17(4), 10-13.
\end{tabular}

The library module was successfully launched as part of the ES1050 course site in Sakai in November 2012. Right after the launch, one librarian presented a lecture to inform students about the availability of the module and the online quiz in Sakai. The librarian also promoted the upcoming in-person library tutorial sessions during the lecture. Furthermore, we announced the launch of the library module on the Announcement Board in Sakai and via e-mail. Four optional library tutorial sessions were held at the end of January 2013 to provide in-person research support to students, as part 
of the blended instruction. These sessions were held at a computer lab inside Taylor Library, with library staff present to help students with their course-related research questions individually or in groups. The online quiz was released in Sakai afterward, and the students had two weeks to complete it. This quiz was due several days before the deadline of the SOTA report.

\section{Research Methodology}

\section{Research Questions}

The ES1050 research study aims to answer the following research questions: Is the online library module effective at improving students' information literacy levels? Does the blended approach of this library instruction support students' learning experience? With these questions in mind, we will consider the impact of the blended approach to library instruction on students' learning experience. To answer these questions, this research reflects, first, on the success of the self-directed online library module in teaching students to locate and use reliable information sources for their ES1050 course assignments; and second, on the students' preference and feedback regarding the use of the online versus in-person instructional content. Both qualitative and quantitative research methods were designed to investigate these questions. The quantitative measurements included pre- and post-tests and an online follow-up survey of students, and the qualitative measurement consisted of two focus group studies of students. These measurements and related findings will be described in detail in the following sections.

\section{Recruitment}

We obtained research ethics approval from Western's Research Ethics Board for NonMedical Research Involving Human Subjects in November 2012. Right after that, we recruited research participants by introducing our research study during all nine ES1050 lab sessions and encouraging students to participate to help us improve future library instruction for this course. The study was completely voluntary. There were no instructors or teaching assistants in the classroom while we recruited research participants, so that the students would not worry about their course mark being influenced by their choice to participate or not. We recruited 252 students out of the 413 enrolled in the course to participate in this study.

Because participation was voluntary, it is possible that only the highest-achieving or most motivated students volunteered, resulting in a subset of students who are not representative of the class as a whole. Volunteer bias is reduced when subjects are interested in the study or perceive it to have practical value, when the study is nonthreatening and anonymous, when participation is requested by a familiar person or one with perceived authority, when there is incentive to participate, and when participation is as short and simple as possible. ${ }^{28}$ This study meets several of these criteria: it had practical value to participants' course assignments, participation or nonparticipation was not shared with instructors or teaching assistants, and the pre-test and follow-up survey took a short amount of time in a class they were already attending. Also, with the online quiz worth 2 percent of their course grade, there was some incentive for all students to take the pre-test as practice for the quiz that would be graded. The strong participation rate and wide range of scores on the pre-test suggest that a cross-section of students took part in the study.

The pre-test was conducted on paper in November 2012 after the participants signed the research study consent form. Only library staff was present while the students worked on the pre-test question set. The post-test was integrated into Sakai. While the pre-test was voluntary and only for research participants to take, the post-test in Sakai was a required part of the course as the course coordinator thought this would 
motivate students to use the module. Although the post-test was a mandatory part of the course, release of test results to the study was voluntary and researchers did not have access to the grades of students who did not choose to participate in the study. After they completed the online post-test in Sakai, research participants were invited to fill out an online follow-up survey (also in Sakai) to share with us their experiences using the library module. In early March 2013, two focus group sessions were held to gather more detailed and specific information from students about their experience with the online module and its usefulness as they prepared their ES1050 assignments. All students taking part in the study were invited via e-mail to attend one of the sessions.

Two hundred and thirty-nine of the 252 recruited participants completed both pre- and post-tests, which results in a participation rate of 57.9 percent of the students enrolled in the course. A total of 89 filled out the online follow-up survey, and seven attended the focus groups. The low response rate to the focus groups may be because participants had just completed two quizzes and a survey and were experiencing participant fatigue or declining interest, because motivation was waning after their course assignments were complete and their term was winding down, or for a reason unknown to the researchers. Although this is not a statistically significant sample size, we still gathered some useful information from the focus group sessions.

\section{Quantitative Measurements}

The pre- and post-tests each contained 15 questions related to information literacy knowledge and skills, testing students at the same information literacy level. The question types included multiple choice questions, true or false questions, and matching questions.

The questions in the pre- and post-tests were designed to test students' basic library and information literacy-related knowledge and to assess students' learning outcomes articulated in the Information Literacy Standards for Science and Engineering/Technology. Topics of the questions included Boolean operators, scholarly versus popular sources, patents, and engineering handbooks. We designed the pre- and post-tests at the same time, before recruiting research study participants. For each concept or knowledge that we wanted to test, we designed two questions that addressed the same concept or knowledge but with different wording, different answer options, or different ordering of answer options. By doing this, we ensured that we would test students' information literacy knowledge at the same level in the pre- and post-tests. The questions in the pre- and post-tests were intentionally not identical to prevent students who opted in to the study and took the pre-test from having previous knowledge, and thus an advantage, in the post-test over those who did not sign up for the research study and did not take the pre-test. (See the pre- and post-test question sets in appendices 1 and 2.)

Each of the 15 questions in the pre- and post-tests was equally weighted, with one point for each. The graded results of the voluntary pre-test were only used as a benchmark for the research study and were not available to students. We only used the post-test results of those students who opted in to the research study to ensure that we had the same research subjects in the pre- and post-test groups. The pre-tests were manually graded by the research team. We assigned each participant a unique participant code (ID number) and organized their quiz scores in a spreadsheet (later transferred to a SPSS file for data analysis) by their ID numbers. The pre-test papers with grading information were locked in the research team lead's office to ensure security and confidentiality. After the closing date of the online post-test, all entries were graded automatically in Sakai and the research team was able to retrieve the scores.

From the 15 question pairs, we compared students' performance on ten matching question sets from the pre- and post-tests. We identified these ten question sets as they were direct matching sets between the pre- and post-tests. The remaining five questions 
tested the same information literacy concepts, but the questions were designed to be less parallel so that the pre- and post-tests were not simply reworded versions of the same test. The ten selected questions included some general information literacy questions as well as some related to engineering-specific information literacy knowledge (such as knowledge about patents and engineering standards). For each question, we also recorded the media format in which the tested information had been presented in the online module. Results and comparative analysis are provided in the Quantitative Measurements section under Research Findings.

The online follow-up survey was intended to help us understand students' preferences for self-paced online learning versus in-person instruction, and the general usefulness of the library module as perceived by students. We designed eight survey questions, some of which had subquestions, to elicit students' feedback. Questions were designed to find out students' preferences among the different instructional and learning modes (in-person instruction, self-paced online learning, and blended learning), students' use of content presented in different formats/media, the frequency and length of time spent using the module, and so on. Survey questions can be found in appendix 3 , and the analysis of survey results is available in the section Survey to Students under Research Findings.

\section{Qualitative Measurement}

The research team conducted two focus groups after the students completed the post-test quiz and the online follow-up survey, in order to gather students' feedback on the use of the library module. Both focus groups were led by a librarian on the research team, and notes were taken by another team member. There was no audio or video recording of these sessions. See the questions asked at focus group sessions in Appendix 4 and the analysis of the focus group findings in the section Focus Groups under Research Findings.

\section{Research Findings}

\section{Quantitative Measurements}

\section{Pre- and Post-test}

Because of the pre- and post-test setup of the study and the statistical values we wanted to measure, a t-test was run to determine if the pre- and post-test scores are significantly different. ${ }^{29}$ We wanted to see whether and how much the average of the post-test scores differs from that of the pre-test scores. Because the two sets of test scores we are comparing came from a single sample of study participants, a related or correlated t-test was specifically run for this study. ${ }^{30}$ The $t$-test results below demonstrate the significance of the difference between the averages of the pre- and post-test scores. Tables 1 and 2 below, generated by IBM SPSS Statistics 21, show the t-test results of the study's test data.

Table 1 shows the mean (or the average) and standard deviation (SD) of the pre- and post-test scores. In table 2, we report the two-tailed significance level, $p$ as $p<0.001$, from the t-test analysis. The $p$ value we obtained is less than 0.001 , meaning the probability for the means of the pre- and post-test scores not being significantly different is minimal, thus proving that the means of these two sets of scores differ significantly. As

\begin{tabular}{|l|c|c|c|c|}
\hline \multicolumn{5}{|c|}{ TABLE 1 } \\
\multicolumn{5}{|c|}{ Paired Samples Statistics } \\
\hline & Mean & N & Std. Deviation & Std. Error Mean \\
\hline Pre-test & 10.456 & 239 & 2.0715 & .1340 \\
\hline Post-test & 13.843 & 239 & 1.5138 & .0979 \\
\hline
\end{tabular}




\begin{tabular}{|c|c|c|c|c|c|c|c|c|c|}
\hline \multicolumn{10}{|c|}{$\begin{array}{c}\text { TABLE } 2 \\
\text { Paired Samples Test Results }\end{array}$} \\
\hline & & \multicolumn{5}{|c|}{ Paired Differences } & \multirow[t]{3}{*}{$\mathrm{t}$} & \multirow{3}{*}{$\begin{array}{l}\text { df } \\
\text { (degree } \\
\text { of } \\
\text { freedom) }\end{array}$} & \multirow{3}{*}{$\begin{array}{l}\text { Sig. } \\
\text { (2-tailed) }\end{array}$} \\
\hline & & \multirow[t]{2}{*}{ Mean } & \multirow[t]{2}{*}{$\begin{array}{c}\text { Std. } \\
\text { Deviation }\end{array}$} & \multirow[t]{2}{*}{$\begin{array}{l}\text { Std. } \\
\text { Error } \\
\text { Mean }\end{array}$} & \multicolumn{2}{|c|}{$\begin{array}{l}95 \% \text { Confidence } \\
\text { Interval of the } \\
\text { Difference }\end{array}$} & & & \\
\hline & & & & & Lower & Upper & & & \\
\hline $\begin{array}{l}\text { Pair } \\
1\end{array}$ & $\begin{array}{l}\text { Pre- } \\
\text { test- } \\
\text { Post-test }\end{array}$ & -3.3870 & 2.4873 & .1609 & -3.7040 & -3.0701 & -21.052 & 238 & .000 \\
\hline \multicolumn{10}{|c|}{$(\mathrm{t}=-21.052, \mathrm{df}=238$, two-tailed $\mathrm{p}<0.01)$} \\
\hline
\end{tabular}

the average of the post-test scores is higher than the average of the pre-test scores, we can conclude that the post-test scores are significantly higher than the pre-test scores, given the sample size of the study participants.

\begin{tabular}{|c|c|c|c|c|}
\hline \multicolumn{5}{|c|}{$\begin{array}{c}\text { TABLE } 3 \\
\text { Question-Level Analysis for Ten Matching Question Sets }\end{array}$} \\
\hline $\begin{array}{l}\text { Question } \\
\text { Content }\end{array}$ & Presentation Format & $\begin{array}{l}\text { Pre-test } \\
\text { (Correct) }\end{array}$ & $\begin{array}{l}\text { Post-test } \\
\text { (Correct) }\end{array}$ & $\begin{array}{l}\text { Absolute } \\
\text { Increase }\end{array}$ \\
\hline $\begin{array}{l}\text { Interpreting } \\
\text { Journal Article } \\
\text { Citations }\end{array}$ & $\begin{array}{l}\text { Interactive web-based content } \\
\text { with images and rollover effect }\end{array}$ & $\begin{array}{l}\text { Q12 } \\
41.8 \%\end{array}$ & $\begin{array}{l}\text { Q13 } \\
95.0 \%\end{array}$ & $53.2 \%$ \\
\hline $\begin{array}{l}\text { Concept of } \\
\text { Patents }\end{array}$ & Text & $\begin{array}{l}\text { Q10 } \\
50.6 \%\end{array}$ & $\begin{array}{l}\text { Q11 } \\
86.6 \%\end{array}$ & $36 \%$ \\
\hline $\begin{array}{l}\text { Identifying } \\
\text { Reliable Sources }\end{array}$ & $\begin{array}{l}\text { Interactive web-based content } \\
\text { with images and rollover effect }\end{array}$ & $\begin{array}{l}\text { Q4 } \\
62.8 \%\end{array}$ & $\begin{array}{l}\text { Q4 } \\
97.9 \%\end{array}$ & $35.1 \%$ \\
\hline Search Strategy & $\begin{array}{l}\text { Video, text, and diagrams } \\
\text { hyperlinked from the page }\end{array}$ & $\begin{array}{l}\text { Q3 } \\
54.0 \%\end{array}$ & $\begin{array}{l}\text { Q3 } \\
87.0 \%\end{array}$ & $33 \%$ \\
\hline $\begin{array}{l}\text { How to Read a } \\
\text { Journal Article }\end{array}$ & Video and text & $\begin{array}{l}\text { Q13 } \\
79.1 \%\end{array}$ & $\begin{array}{l}\text { Q14 } \\
96.2 \%\end{array}$ & $17.1 \%$ \\
\hline $\begin{array}{l}\text { Concept of } \\
\text { Engineering } \\
\text { Handbooks }\end{array}$ & Text & $\begin{array}{l}\text { Q7 } \\
82.4 \%\end{array}$ & $\begin{array}{l}\text { Q9 } \\
97.9 \%\end{array}$ & $15.5 \%$ \\
\hline $\begin{array}{l}\text { Boolean } \\
\text { Operators }\end{array}$ & Video and text & $\begin{array}{l}\text { Q2 } \\
63.6 \%\end{array}$ & $\begin{array}{l}\text { Q2 } \\
72.4 \%\end{array}$ & $8.8 \%$ \\
\hline $\begin{array}{l}\text { Concept of Peer- } \\
\text { Review Process }\end{array}$ & Video and text & $\begin{array}{l}\text { Q5 } \\
87.9 \%\end{array}$ & $\begin{array}{l}\text { Q6 } \\
94.6 \%\end{array}$ & $6.7 \%$ \\
\hline $\begin{array}{l}\text { Concept of } \\
\text { Engineering } \\
\text { Standards }\end{array}$ & Text & $\begin{array}{l}\text { Q9 } \\
92.9 \%\end{array}$ & $\begin{array}{l}\text { Q10 } \\
99.2 \%\end{array}$ & $6.3 \%$ \\
\hline $\begin{array}{l}\text { Identifying } \\
\text { Plagiarism Cases }\end{array}$ & Video & $\begin{array}{l}\text { Q15 } \\
93.3 \%\end{array}$ & $\begin{array}{l}\text { Q15 } \\
99.6 \%\end{array}$ & $6.3 \%$ \\
\hline
\end{tabular}


With the library module and tutorial sessions being the primary interventions in this study, we can conclude that the online module along with the in-person tutorials played a positive role in improving the students' information literacy levels, which were measured by the questions in our pre- and post-tests.

Table 3 summarizes the question-level analysis of the ten correlated questions from the pre- and post-tests. It lists the correlated questions in order of how much student performance increased from pre-test to post-test. The first four questions in the table saw considerably higher improvement than the remaining six questions. These questions were presented in a variety of different formats, including videos and interactive HTML text, and covered developing a search strategy, identifying reliable sources, finding patents, and interpreting journal article citations. More details are presented in the Discussion section Lessons Learned for Future Library Instruction Development.

\section{Survey to Students}

The first survey question asked what resources the students used to find literature for their ES1050 assignments. Despite being presented with a range of resources in the module, many students still used Google or other free web search engines to find relevant literature for their course project. However, 60 percent of the respondents reported using the library module to get started finding literature.

All subsequent questions were single-choice or Likert scale questions. When it came to how the module content was used, students were divided between those who watched all, some, or none of the videos that were embedded in the library module. Overall, two thirds of the respondents watched the videos. When asked about the most helpful part of the library module, slightly more chose text than videos. Students' preference for text over videos was insignificant, suggesting both probably played a nearly equal part in helping students understand the content. Only a few students indicated that the interactive activities provided by the module were the most helpful.

Students were also closely split between those who used the module all at once and those who used it a little at a time. Most used the library module either only before they started their project or only after they started their project. This implied that students used the module for acquiring basic information and skills before working on the project or that they checked the module on an as-needed basis while working on their project. Either way, we can conclude that most students used the module purposefully. Three quarters of students spent more than 30 minutes using this module, which is a reasonable length of time to complete the module, while the remaining quarter spent less than half an hour. When asked about the organization of the module content, more than half of the students agreed that the content was well organized and that they were able to find the information they needed.

The majority of students reported that they gained confidence using library resources after completing the library module, with only a very small number of students indicating otherwise. Students also consistently reported that the library module helped them research strategically and effectively and made them more aware of the big picture of library research in engineering. Most of the students expressed that the module contained the right amount of information to help them work on their assignments.

After using the module, 40 percent of students said that they would have preferred an in-class demonstration of library resources. This shows a moderate preference for online instruction, which may indicate that students generally do not have a strong preference for one instruction delivery mode. In keeping with the low attendance at the library tutorial sessions, most respondents were undecided about the helpfulness of these sessions. 


\section{Qualitative Measurement}

\section{Focus Groups}

In general, the focus group findings confirm the results of the follow-up survey but offer added insight that will help us to improve the module for future students. Discussion at the focus group sessions was structured around nine open-ended questions about the content and usage of the module along with ways that it could be improved. Participants felt that the content of the module was helpful, particularly the sections about Boolean searching, avoiding plagiarism, and citing sources, and that it made them more aware of Western Libraries' resources and facilities.

All the participants reported satisfaction with the self-paced learning experience, preferring it to in-class library instruction. They appreciated that self-paced learning allowed them to work on the module at their convenience, that it was low pressure, and that it provided the opportunity to review content when needed. They acknowledged, however, that self-paced learning requires self-motivation and suggested that more quizzes be built into the module to counter this and to reinforce learning. Finally, participants in the focus group sessions stressed that the module was useful and helped them with their assignments.

We also received some suggestions for improvement. Most participants said they had no technological barriers, but some did encounter technical problems. The students were also divided on the look of the module-some liked the colour, layout, and balance of text and images, but others found it unappealing and text-heavy. However, the design of the module was limited by the features in Sakai.

None of the focus group participants attended the library tutorials, stating that the material was not complicated enough to require in-person help. We also learned that we may have held the tutorials too early - participants believed that help is needed a day before the assignment is due, or even the same day, and students are unlikely to seek help before that.

Overall, the focus group participants praised the module and felt that the skills learned were transferrable to other assignments and courses. They also recommended advertising or recruiting student ambassadors to spread the word about the module and its usefulness, having instructors and TAs remind them about the module, and promoting the way to access the module in Sakai.

\section{Discussion}

\section{Effectiveness of the Library Instruction}

Our study shows that the library module was effective at improving students' information literacy levels. The large pool and single sample of study participants combined with the pre- and post-test setup warranted the use of a paired t-test to measure the significance of the differences between the two sets of test scores. The average score (mean) on the pre- and post-tests rose from 10.456 (pre-test) to 13.843 (post-test). Given the fact that the pre- and post-tests were designed to measure the same information literacy knowledge and skills at an equal level of difficulty, the significant increase in mean scores from pre- to post-test suggests the positive impact of the library instruction (delivered mainly via the online library module) on students' information literacy levels.

We also discovered from the student survey results that, in general, students found the content presented in the module useful while working on the ES1050 assignments, which demonstrates the effectiveness of the online module content from the students' perspectives. Most students appreciated the self-paced learning style that the module enabled, which suits a range of work habits and preferences. Students' slight preference for online instruction over in-person instruction also suggests the benefits of the online delivery mode. The focus groups, though they had limited attendance, support the findings mentioned above. 


\section{Implementation of the Blended Learning Approach}

We designed the ES1050 library instruction to be a blended approach with relatively balanced components of online and in-person instruction; however, there was less uptake of the in-person instruction. With students coming in and out, we estimate that about 15 students attended the four library tutorial sessions. The low attendance rate indicates a less-than-ideal blended learning experience for students. There are several possible reasons for this: First, students might have been unsure if the tutorials would be helpful to them. They might have been unfamiliar with the concept of library tutorials or been unsure what they could get out of these sessions. This aligns with our findings from the student survey. Second, the timing of these tutorial sessions (two months before the SOTA report's deadline) might not have motivated the students to attend, as students tend to work on their assignments closer to the deadline. Third, some students may have thought that there was no need to seek in-person help from these sessions since they were able to finish their assignments without such help.

Scholars such as Churkovich and Oughtred; Joint; Kraemer, Lombardo, and Lepkowski; and Usova discovered in their studies that blended learning provides flexible learning experiences for students and helps improve students' performance. ${ }^{31}$ Our study findings aligned with these observations. Students appreciated the flexibility of the self-paced learning experience, and the pre- and post-test results indicate improvement of their information literacy skills.

To adjust the learning approach into a more ideal blended learning experience, we made the in-person learning component mandatory for the 2014-2015 academic year by adopting the flipped classroom pedagogy. The online module was the instruction delivered before the class. During the class, the instruction librarian reviewed the module content and incorporated hands-on exercises for the students to apply what they had learned from the module, which helped reinforce their understanding of the content.

\section{Challenges of First-year Engineering Students}

First-year students, in general, may face challenges orienting themselves to the university system, including the library system. Based on our preliminary question-level analysis of the correlated questions in the pre- and post-tests (refer to table 3), students might have more difficulty identifying plagiarism cases, understanding the citation information of sources, and properly using Boolean operators in developing search strategies. From our anecdotal experience, first-year engineering students often face challenges understanding and finding the diverse types of engineering sources (scholarly articles, standards, handbooks, patents, and so on). The rapid development of knowledge and information required in engineering subject areas might also lead to information overload for first-year engineering students. To help students effectively overcome these challenges, it is necessary to integrate tailored library instruction with appropriate delivery mode as part of their curriculum.

The online library module's page in Sakai was used by the librarian in all in-person interaction with students. Our experience confirmed the importance of combining in-person instruction with detailed course-specific library content, a recommendation made by Barsky, Read, and Greenwood. ${ }^{32}$ They also stressed that it is essential to have engineering-specific library resources tailored for and delivered to engineering students in the first two years of their studies. The library module we developed covered both general and engineering-specific information sources, and we found that this coverage of engineering-specific sources was helpful for the students to do their reports and search log assignments. 


\section{Lessons Learned for Future Library Instruction Development}

We discovered from the question-level analysis that students showed greater improvement on some questions than on others. Four question sets (see table 3) observed a more than 30 percent increase in correct responses. These questions were used to test knowledge and skills about search strategy, reliable source identification, definition of patents, and citation interpretation. The question students improved on the most was about interpreting journal article citations. The related information was presented in interactive HTML text. This might imply the effectiveness of interactive text on students' positive learning outcomes, or it may indicate that students had a greater deficiency in their knowledge of this topic to begin with. However, given the small question pool for the pre- and post-tests, we cannot draw these general conclusions from this study's results alone. The same analysis raised an interesting question about whether multimedia (videos in particular) rather than text better promotes students' learning experience and subsequently improves their information literacy levels. This question is outside the scope of the current study but is worthy of further consideration.

With student engagement kept at the forefront, we collaborated with faculty to understand the students' information literacy needs, and we also designed a thorough assessment plan to gauge students' responses to blended learning and evaluate the effectiveness of this instructional mode on students' information literacy levels. These components align with the "pillars of effective information literacy instruction" described by Held. ${ }^{33}$ The assessment results not only helped answer our research questions but also provided valuable insight for improving the library module's design and implementation, as well as direction for future research studies. We also consulted extensively with ITRC and LITS for necessary help during the module development and for support during implementation. Based on our experience, we can confirm the necessity and importance for library staff to collaborate with different stakeholders on campus, including library or university IT, instructional designers, and faculty members, when working on library e-learning projects.

Sakai, Western's CMS in this study, was a useful tool for designing the library module and the assessment pieces, including quizzes and surveys. As Kraemer, Lombardo, and Lepkowski point out, the embedded evaluation feature in CMS provides a convenient way for librarians to evaluate student learning outcomes and to store and analyze test results. ${ }^{34}$ We also used other features in Sakai, such as embedding videos to engage students' learning and making announcements to promote the library module, and we found these features useful and applicable for online information literacy instruction. Based on our experience designing and implementing the module and the findings of the study, we would recommend CMS as a delivery and assessment tool that works well for both students and librarians.

Students' performance improvement and feedback suggest that it was worth the time and effort to develop and integrate the module into a specific course, even though it meant substantial staffing time. This aligns with the observations and recommendations of several other scholars. ${ }^{35}$ To maximize the benefit of the self-paced online learning experience favored by the students, we will be exploring the different features offered by Sakai for future delivery of the library instruction. We plan to implement online office hours, text and voice discussion forums, and more. Other CMS software programs also offer similar features, which we encourage our library colleagues to explore and implement to better support students' online learning experience.

\section{Future Research}

To improve the study, future measurement could involve two sets of questions that test students' information literacy skills at an identical level, for the same sample 
pool before and after the use of the library module. For example, if we recruit 100 students for this future study, we could have 50 students work on Question Set A and the other 50 students work on Question Set B during the pre-test. After the use of the library module, during the post-test, we would have the 50 students who worked on Question Set A complete Question Set B and vice versa. Ideally, the pre- and post-tests would both be either voluntary or mandatory, which would eliminate the potential for a certain group of students having an advantage over the others by taking the pre-test. Before implementing the study, we would also ask some first-year nonengineering students to complete both question sets to verify whether the difficulty levels are identical. This approach might help to ensure that measurements for the pre- and post-tests have the same difficulty levels, which could further confirm the direct correlation between the use of the library module and students' performance change.

It would be beneficial to have several participant groups receiving the same information literacy instruction content using different instructional modes. For example, having one group receive face-to-face instruction, another group receive online instruction, and a third group receive blended learning would allow us to compare the learning outcomes of each group. Future research should also attempt to explore first-year students' existing information literacy skills (information literacy training before entering university) to provide insight into the integration of tailored information literacy components into their curriculum. This would also ensure more accurate assessment results of the research at the individual level.

For future studies, it would also be helpful to obtain demographic information such as participants' age, gender, and status (domestic or international) when we recruit research participants or during one of the measurements (pre- or post-test or survey) to allow us to conduct relevant analysis. This demographic information could be used to investigate other factors potentially influencing students' performance changes given the same information literacy instruction, which might include their previous information literacy background, previous library experience, and even possibly language barriers for international students. We are also interested in investigating whether there is a correlation between the medium or format in which information is presented and students' learning outcomes.

\section{Conclusion}

This research study was conducted with students in a first-year engineering course, using a newly developed online library module with optional in-person research support, to evaluate the outcomes of library information literacy instruction through this blended approach. The study bridges the literature gap in the area of evaluating blended learning for first-year engineering undergraduate students. The library module consisted of a range of formats of information and was designed to support students with different learning styles and preferences. This blended instruction, in particular the self-paced learning experience the online module enabled, was well received by the majority of students. Recently, we also enhanced our original blended approach by implementing a flipped classroom model to provide a more balanced combination of online and in-person library instruction.

Test results show that the students achieved a significant improvement in their information literacy skills and knowledge after completing the online module. Focus group and online survey results indicate that the online module was preferred by many students over in-class lectures because of the self-paced nature of the learning. The study findings also show that the content of the library module was helpful to them when learning how to conduct research for their course assignments. We received positive 
feedback regarding the use of various formats of content in the module, although a more user-friendly design was suggested for future students enrolled in this course.

This study also demonstrates that best practices of online library instruction require collaboration with teaching faculty, careful course integration and content design, appropriate choices of e-learning technologies, and IT support. The online instructional approach, combined with in-person contact with subject librarians, provides students with the flexibility to learn from different formats of materials at their own pace and also reduces library staff workload over in-class teaching, especially for courses with large student enrolments.

Furthermore, this research provides an example of pedagogical changes to library instruction in undergraduate engineering programs. Integrating online or blended library instruction into the curriculum offers an excellent opportunity for engineering librarians to partner with course instructors to support and promote e-learning initiatives, which are also part of the goals and objectives of the library, the engineering faculty, and the university.

\section{Acknowledgements}

We would like to acknowledge those who helped this research study: Dr. Jonathon Southen, the course coordinator for ES1050 during the 2012-2013 academic year, who greatly supported our research study by giving us class time; Ken N. Meadows, who reviewed our research methods and verified our test measurements; and Kristin Hoffmann and Cara Bradley, who read our manuscript and provided valuable feedback. Funding for this research was provided by Western Libraries in support of the focus groups and for the purchase of software and research materials. 


\section{Appendix 1. Pre-test Question Set}

\section{Pre-test Question Set of the ES1050 Library Module Research Study}

Name
E-mail
Date

1. Which of the following library on campus is the one for Engineering, Science, and Health/Medicine?

A. The D.B. Weldon Library

B. C.B. "Bud” Johnston Library

C. Allyn \& Betty Taylor Library

D. Map \& Data Centre

2. Match each of the following diagrams with the corresponding Boolean operator. Put your choice underneath each diagram.

A. A AND B

B. A OR B
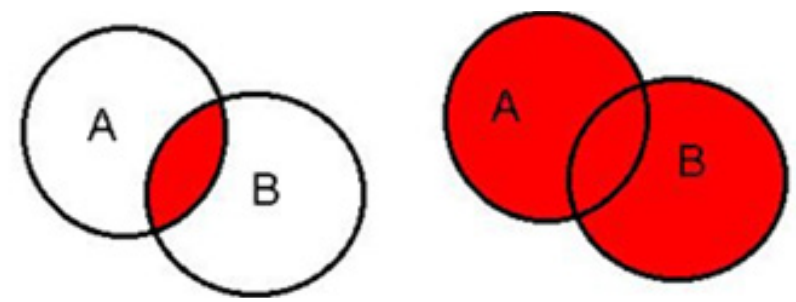

3. True or false:

Below is a correct search statement for the research topic: "The impact of hybrid cars on gas consumption."

(electric cars OR gas consumption) AND (hybrid vehicles or fuel consumption)

Circle your choice here: True False

4. Please identify reliable sources from below that you can use for your ES1050 assignment. Choose all that apply.
A. A Wikipedia page
B. A blog site
C. A journal article
D. Professional Engineers Ontario's website
E. A book found in the Western Libraries' catalogue

\section{Peer review:}

A. Is also called "refereed" in some academic fields

B. Allows an author's work to be critiqued by their peers

C. Is designed to maintain a high quality of publication

D. All of the above

6. The cover of a scholarly publication is often:

A. Flashy and attractive to its readers

B. An advertisement for laboratory equipment

C. Featuring a celebrity scientist

D. Consistent from month to month 
7. An engineering handbook is:

A. A source that outlines how to conduct research and write essays in a particular discipline

B. A source written by experts in a field that provides overview information and basic introduction to the field

C. A source containing articles on a specific topic written by a professional writer

D. A source that shows you how to format your footnotes and bibliography

8. True or false: To find a specific book on the library shelf, you need a call number and library location.

Circle your choice here: True False

9. Engineering standards are:

A. Established norms or requirements for technical systems, designs, or experiments

B. Formalized by private organizations or individual institutions

C. Used to ensure that a particular design follows the cutting-edge technologies

D. Optional to refer to when designing engineering projects or protocols

10. Which of the following statements is NOT correct for patents? Patents:

A. Are a set of descriptions, diagrams, and materials for a particular research discovery

B. Are legal documents that give details of inventions

C. Grant the inventor rights to that invention for an indefinite period of time

11. Where can you find print or electronic journal articles for your essays? Choose all that apply.
A. Western Libraries' catalogue
B. Drug stores
C. Western Libraries' branches
D. Databases on Western Libraries' website

12. Which of the following is the volume number of this journal issue?

Miller, J. R. (2012). Real-Time Visualization of Domain Coverage by Dynamically Moving Sensors. IEEE Computer Graphics and Applications 32 (4): 8-13.
A. 32
B. 4
C. 2012
D. $8-13$

13. To get a brief overview of a journal article, you should start with:
A. Methods
B. Title and Abstract
C. Discussion
D. Title and Results

14. A bibliography is:
A. A book of drawings or charts
B. A book about the life of someone
C. A list of references or citations
D. An essay about libraries 
15. Which of the following is considered plagiarism?
A. Paraphrasing a paragraph from a source in your own essay and incorrectly identify the author and/or the publisher in the reference section
B. Copying and pasting a few sentences from a source in your own essay with- out giving the original author credit
C. Changing or reordering a few words in a sentence and using it in your own essay
D. Ask a friend to write up a paper for you and submit it for your assignment
E. All of the above

\section{Appendix 2. Post-test Question Set}

\section{Library Module Quiz}

Welcome to the online quiz of the ES1050 Library Module. Please complete and submit the quiz within 15 minutes. You can only take the quiz once, and late submission will not be accepted. You will be able to view your result and feedback after you submit the quiz.

1. Which of the following library on campus is the one for Engineering, Science, and Health/Medicine?
A. The D.B. Weldon Library
B. Map \& Data Centre
C. Allyn \& Betty Taylor Library
D. C.B. "Bud" Johnston Library

2. Match each of the following scenarios with the statement applying the right Boolean operator.

1. "AND" A. To combine different concepts

2. “OR" B. To combine synonyms or similar terms

3. You are given the following topic: "The impact of hybrid cars on gas consumption." Which of the following is the best keyword search for the given topic?
A. ("hybrid vehicles" OR "electric cars") AND ("fuel consumption" OR "gasoline consumption")
B. ("hybrid cars" AND "electric cars") OR ("gas consumption" AND "fuel us- age")
C. ("electric cars" OR "gas consumption") AND ("hybrid vehicles" OR "fuel consumption")

4. Which information source on the list below would be considered a scholarly source for researchers at academic and research institutions?
A. Blogs
B. Magazines
C. Journals
D. Newspapers

5. Which of the following options is NOT important when evaluating a website to be used for your SOTA report?
A. Restricted access
B. Relevance 

C. Authority
D. Currency
E. Purpose

6. Articles submitted to a peer-reviewed journal:

A. Can be accepted or rejected by the reviewers

B. Are reviewed only by the journal editor

C. Are published within one week to get the news out fast

7. Helpful places or ways to locate scholarly information do NOT include
A. Databases by Subject list on the Western Libraries website
B. Program Guides on the Western Libraries website
C. The magazine section in Shopper's Drug Mart
D. Journal title search in Western Libraries' catalogue

8. Popular resources are often written by:
A. Experts in the field
B. Students
C. Professional writers
D. All of the above

9. Where can you locate engineering handbooks?
A. Web of Science
B. ENGnetBASE
C. ASTM website
D. esp@cenet

10. Engineering standards:
A. Allow you to perform an experiment any way you want.
B. Are established norms or requirements for technical systems, designs, or experiments.
C. Are formalized by private organizations or individual institutions.

11. Patents:
A. Grant the inventor rights to that invention for an indefinite period of time
B. Are legal documents that give details of inventions
C. Include technologies that always appear in journal articles

12. There are different databases accessible via the library website for you to locate journal articles.

True False

13. Which of the following is the title of this journal article? Miller, J. R. (2012). Real-Time Visualization of Domain Coverage by Dynamically Moving Sensors. IEEE Computer Graphics and Applications 32 (4): 8-13.

A. IEEE Computer Graphics and Applications

B. Real-Time Visualization of Domain Coverage by Dynamically Moving Sensors

14. From which part of a journal article can you find a list of relevant articles?
A. Abstract
B. Introduction 
C. Discussion and Conclusion

D. References/Bibliography

15. Which of the following is/are considered plagiarism?
A. Paraphrasing a paragraph from a source in your own essay and incorrectly identify the author and/or the publisher in the reference section.
B. Copying and pasting a few sentences from a source in your own essay with- out giving the original author credit.
C. Changing or reordering a few words in a sentence and using it in your own essay.
D. Asking a friend to write a paper for you and submitting it for your assign- ment.
E. All of the above

\section{Appendix 3. Online Follow-up Survey Questions to Students}

\section{Online Follow-up Survey}

\section{Disclaimer}

This post-test survey will be conducted electronically in Sakai right after the students complete their online quiz, if they choose to opt into the study. A detailed consent document is attached here. The research group will work with ITRC or ITS to embed the survey in Sakai for those students who opt into the survey. A pilot test of these survey questions will be run before the research group finalizes them.

\section{To find relevant literature for my ES1050 project, I:}

- used the library module

- attended a library drop-in session

- requested library research help

- searched Google or other free web search engines

- consulted with a classmate or friend

- others, please specify:

2a. When using the library module, I:

- watched all the videos

- watched some of the videos

- skipped the videos

$2 \mathrm{~b}$. When using the library module, I:

- read all the text

- read some of the text

- skipped the text

3. What was the most helpful part of the library module:

- the videos

- the text

- the interactive activities (that is, sample websites for evaluating sources)

- the images from the library website

- the module as a whole 
4. When going through the module content,

- I went through the module all at once.

- I viewed the content a little at a time, going to the section I needed.

5. I used the library module:

- before beginning my project

- after I had started my project

- both

6. How many times did you visit the module while preparing your assignment?

- Only once

- 2-3

- 4-5

- 6 or more

7. In total, how long did you spend using this module?

- Less than 30 minutes

- 30 min. -1 hr.

- 1 hr. -2 hr.

- 2 hr. -3 hr.

- More than 3 hours

8. Rate each statement below based on how much you agree or disagree with it. Likert scales at the bottom will be given for each of the following statement.

- I have more confidence using library resources after using the library module.

- The library module made me more aware of the bigger picture of library research in engineering.

- The library module had the right amount of information to help me complete my assignment.

- The library module helped me get started with my research.

- The library module helped me research more strategically/effectively.

- The information in this module was interesting.

- I would have preferred an in-class demonstration of library resources.

- The library drop-in session I attended helped me to understand the information covered by the library module.

- The library module was organized into sections that made sense to me; I could find the information I needed.

\section{Likert scale}

\begin{tabular}{|c|c|c|c|c|}
\hline Strongly Disagree & & Neutral & & Strongly Agree \\
\hline $\mathbf{0}$ & $\mathbf{0}$ & $\mathbf{0}$ & $\mathbf{0}$ & $\mathbf{0}$ \\
\hline
\end{tabular}




\section{Appendix 4. Focus Group Discussion Questions}

\section{Disclaimer}

A focus group will be conducted after the post-test survey. The main objective of the focus group study is to gather qualitative data that could inform the online library module's effects on students' information literacy level based on their learning experience. We are particularly interested in whether the video tutorials embedded in the module affected students learning.

Discussion in the focus group will also involve investigations of students' preferences among self-paced modules, in-person instruction, and a hybrid learning model of both. We also would like to gather students' feedback on the library module from a pedagogical perspective to develop best practices of designing online library modules in the future.

During the focus group, open-ended questions and semistructured interview questions similar to the following will be asked to lead the discussion.

A detailed consent document and an e-mail reminder template are attached here. Again, a pilot test will be conducted before finalizing these discussion questions.

1. Did you find the module helpful in general? Was it helpful for your ES1050 assignment?

2. Tell me one thing that you learned from the module that helped you with your assignment.

3. Did you learn anything from any of the videos we embedded in the module? If so, tell me which one(s).

4. Did you go through the module all at once or view the content a little at a time to accommodate your needs at the moment?

5. Did you enjoy the self-paced learning experience? Or do you prefer in-class lecturing? Or a hybrid of both?

6. Tell me one thing that you did NOT like about the module.

7. Did you have any difficulties viewing any part of the module? Any technology barriers?

8. What would you recommend that we change in the module? Could be anything, such as content, layout, font size.

9. What could we improve in this library module for future ES1050 students? Any suggestions?

\section{Notes}

1. American Library Association, ACRL Guidelines for Instruction Programs in Academic Libraries, available online at www.ala.org/acrl/standards/guidelinesinstruction [accessed 15 October 2013].

2. American Library Association, Information Literacy Standards for Science and Engineering/ Technology, available online at www.ala.org/acrl/standards/infolitscitech [accessed 13 August 2012].

3. Karen Anderson and Frances A. May, "Does the Method of Instruction Matter? An Experimental Examination of Information Literacy Instruction in the Online, Blended, and Face-to-Face Classrooms," Journal of Academic Librarianship 36, no. 6 (Nov. 2010): 495-500; Carol Anne Germain, Trudi E. Jacobson, and Sue A. Kaczor, "A Comparison of the Effectiveness of Presentation Formats for Instruction: Teaching First-Year Students," College \& Research Libraries 61, no. 1 (Jan. 2000): 65-72; James Nichols, Barbara Shaffer, and Karen Shockey, "Changing the Face of Instruction: Is Online Or In-Class More Effective?” College E Research Libraries 64, no. 5 (Sept. 2003): 378-88; 


\section{Integrating Library Instruction into the Course Management System 957}

Li Zhang, Erin M. Watson, and Laura Banfield, "The Efficacy of Computer-Assisted Instruction Versus Face-to-Face Instruction in Academic Libraries: A Systematic Review," Journal of Academic Librarianship 33, no. 4 (Apr. 2007): 478-84.

4. Germain, Jacobson, and Kaczor, "A Comparison of the Effectiveness of Presentation Formats for Instruction," 65-72; Nichols, Shaffer, and Shockey, "Changing the Face of Instruction," 378-88.

5. Marion Churkovich and Christine Oughtred, "Can an Online Tutorial Pass the Test for Library Instruction? An Evaluation and Comparison of Library Skills Instruction Methods for First Year Students at Deakin University," Australian Academic E Research Libraries 33, no. 1 (Mar. 2002): 25-38; Nicholas Joint, "Information Literacy Evaluation: Moving Towards Virtual Learning Environments," Electronic Library 21, no. 4 (Jan. 2003): 322-34; Elizabeth W. Kraemer, Shawn V. Lombardo, and Frank J. Lepkowski, "The Librarian, the Machine, or a Little of Both: A Comparative Study of Three Information Literacy Pedagogies at Oakland University," College E Research Libraries 68, no. 4 (July 2007): 330-42; Tatiana Usova, "Optimizing Our Teaching: Hybrid Mode of Instruction," Partnership: Canadian Journal of Library $\mathcal{E}$ Information Practice $\mathcal{E}$ Research 6, no. 2 (Jan. 2011): 101-12.

6. Churkovich and Oughtred, "Can an Online Tutorial Pass the Test for Library Instruction?" 25-38; Kraemer, Lombardo, and Lepkowski, "The Librarian, the Machine, or a Little of Both," 330-42.

7. Churkovich and Oughtred, "Can an Online Tutorial Pass the Test for Library Instruction?" 25-38; Usova, "Optimizing Our Teaching," 1-12.

8. Barbara Wittkopf, "Recreating the Credit Course in an Online Environment," Reference E User Services Quarterly 43, no. 1 (2003): 18-25.

9. Yvonne Mery, Jill Newby, and Ke Peng, "Why One-Shot Information Literacy Sessions Are Not the Future of Instruction: A Case for Online Credit Courses," College E Research Libraries 73, no. 4 (July 2012): 366-77.

10 Tim Held, "Blending In: Collaborating with an Instructor in an Online Course," Journal of Library E Information Services in Distance Learning 4, no. 4 (Dec. 2010): 153-65.

11. Stephanie Michel, "What Do They Really Think? Assessing Student and Faculty Perspectives of a Web-based Tutorial to Library Research," College E Research Libraries 62, no. 4 (July 2001): 317-32.

12. John D. Shank and Nancy H. Dewald, "Establishing Our Presence in Courseware: Adding Library Services to the Virtual Classroom," Information Technology and Libraries 22, no. 1 (Mar. 2003): 38-43; Elizabeth L. Black and Betsy Blankenship, "Linking Students to Library Resources through the Learning Management System," Journal of Library Administration 50, no. 5/6 (Aug. 2010): 458-67.

13. Black and Blankenship, "Linking Students to Library Resources," 458-67; Eugene Barsky, Kevin Read, and Aleteia Greenwood, "Teaching Matters: Increasing Library Visibility through Integrated Classroom Instruction," Partnership: The Canadian Journal of Library and Information Practice and Research 6, no. 1 (Jan. 2011): 701-05; Kuan-nien Chen and Pei-chun Lin, "Information Literacy in University Library User Education," Aslib Proceedings: New Information Perspectives 63, no. 4 (Jan. 2011): 399-418; Jane Nichols and Margaret Mellinger, "Portals for Undergraduate Subject Searching: Are They Worth it?" portal: Libraries and the Academy 7, no. 4 (Oct. 2007): 481-90.

14. Black and Blankenship, "Linking Students to Library Resources," 458-67; Dorothy Barr, "Reaching Students Where They Go: Embedding Library Resources in Course Content," Science E Technology Libraries 29, no. 4 (Oct. 2010): 289-97.

15. Kristin J. Henrich and Ramirose I. Attebury, "Using Blackboard to Assess Course-Specific Asynchronous Library Instruction," Internet Reference Services Quarterly 17, no. 3/4 (July 2013): 167-79.

16. ALA, Information Literacy Standards for Science and Engineering/Technology.

17. Ibid.

18. Barr, "Reaching Students Where They Go," 289-97.

19. Barsky, Read, and Greenwood, "Teaching Matters," 701-05.

20. Anderson and May, "Does the Method of Instruction Matter?" 495-500; Henrich and Attebury, "Using Blackboard," 167-79.

21. Henrich and Attebury, "Using Blackboard," 167-79.

22. Kraemer, Lombardo, and Lepkowski, "The Librarian, the Machine, or a Little of Both," 330-42.

23. Anderson and May, "Does the Method of Instruction Matter?" 495-500.

24. Sarah Clark and Susan Chinburg, "Research Performance in Undergraduates Receiving Face to Face versus Online Library Instruction: A Citation Analysis," Journal of Library Administration 50, no. 5/6 (2010): 530-42.

25. Barsky, Read, and Greenwood, "Teaching Matters," 701-05. 
26. ALA, Information Literacy Standards for Science and Engineering/Technology.

27. California State University, Chico, Evaluating Information: Applying the CRAAP Test, available online at www.csuchico.edu/lins/handouts/eval_websites.pdf [accessed 12 August 2012].

28. Robert L. Boughner, "Volunteer Bias," in Encyclopedia of Research Design, ed. N. Salkind (Thousand Oaks, Calif.: SAGE Publications, Inc., 2010),1609-11.

29. Faiza Qureshi et al., Introduction to Statistics with SPSS for Social Science, 1st ed. (New York: Pearson, 2012), 145-57.

30. Ibid.

31. Churkovich and Oughtred, "Can an Online Tutorial Pass the Test for Library Instruction?" 25-38; Joint, "Information Literacy Evaluation," 322-34; Kraemer, Lombardo, and Lepkowski, "The Librarian, the Machine, or a Little of Both," 330-42; Usova, "Optimizing Our Teaching," $101-12$.

32. Barsky, Read, and Greenwood, "Teaching Matters," 701-05.

33. Held, "Blending In," 153-65.

34. Kraemer, Lombardo, and Lepkowski, "The Librarian, the Machine, or a Little of Both," $330-42$.

35. Black and Blankenship, "Linking Students to Library Resources," 458-67; Barsky, Read, and Greenwood, "Teaching Matters," 701-05; Chen and Lin, "Information Literacy in University Library User Education," 399-418; Nichols and Mellinger, "Portals for Undergraduate Subject Searching," 481-90. 